\title{
MY LIFE AND RESEARCH IN JAPAN
}

\section{MASHINCHI*}

The day began like every other day - I went as always to Kerman University where I worked as an instructor in mathematics - but everything changed for me when I accidentally saw an announcement that the Government of Japan was offering scholarships to Iranians wishing to pursue further studies abroad. Until then I did not know much about Japan, the sum of my knowledge consisting of what I had seen in old Japanese films; anyway I filled out an application form and sent it off to the Iranian Ministry of Science and Higher Education for forwarding to the Japanese authorities.

Several weeks passed before I was asked to come for a formal interview at the Japanese embassy in Tehran. I was impressed when I saw the many applicants who had come from universities across the country, and was pleased that five of these were from Kerman. Indeed, of the five applicants who won the scholarship, four were from my university, and since Kerman University was then only eight years old, this was a matter of pride for all of us.

The first time I met a person from Japan was at the interview, which was conducted in a very warm and friendly atmosphere. I was

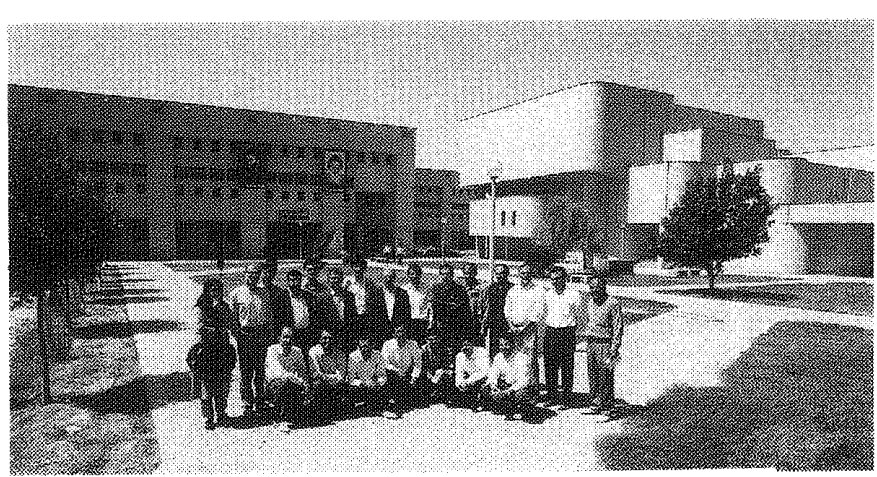

Photo 1 With Friends in Kerman University

Faculty of Mathematics and Computer Sciences, Kerman University, Kerman, IRAN among those who were selected, and we were told that our applications would be forwarded to Japan, where the relevant authorities would seek to place us appropriately. One day I received information that $I$ was admitted to Waseda University, and on October 11, 1983. I arrived in Tokyo with my wife and five-yearold son.

Housing around Waseda University was very expensive, but with the help of Iranian doctoral students studying at Tokyo University and another Iranian who worked with NEC, we found reasonable lodgings in the Ikuta region in the city of Kawasaki, near a campus of Meiji University. Every day I made the long train journey to Tokyo, which was a difficult but interesting experience - at least I was forced to learn colloquial Japanese! Meanwhile my son was busy getting acquainted with the neighboring children, and in spite of the fact that he did not speak any Japanese or English, he made very good friends with the children of a Japanese family living close by. Thus began a friendship between our two families which has lasted to this day. Our Japanese friends were of great help to us, and we went to them whenever we had any difficulty.

At Waseda University I enrolled in Japanese language classes for one year; however after the first six months I started to work on my research as a student in the mathematics department of the faculty of science and engineering. The first Japanese professor I met was my thesis advisor, Professor Hiroshi Noguchi, a professor of mathematics at Waseda University, and I learned much about how to do mathematical research from him. In fact while 
I was at the university, I received encouragement and support from many people, among whom special mention must be made of Professors M.Yamamoto and S.Miyoshi. They helped me with the first papers I wrote [1-5], and these were the basis of my doctoral thesis [6]. I must also express my very sincere gratitude to the families of Hirabayashi, Shimada and Shibata. Without the moral support that they gave my wife and two children(I have a son born in Japan!) I would never have been able to make the long journeys to the university and eventually complete my studies. I graduated from Waseda in March 1987.

I became interested in the theory of fuzzy sets in 1982, and before leaving Japan for Iran (April, 1987). I managed to collect and study several papers on this topic. I had decided to change my field of research when I returned to my country, and the first seminar talk I gave at Kerman University was on the topic of fuzzy sets. A colleague then became interested in the field of fuzzy algebra, and together we published several joint papers [7-11]. A detailed report of our joint research, which also led to the first doctoral thesis [13] written under my supervision, is given in [12].

I now became more and more interested in the applications of fuzzy mathematics, and, because I was also acquainted with Japan, I participated in the International Fuzzy Engineering Symposium sponsored by LIFE and

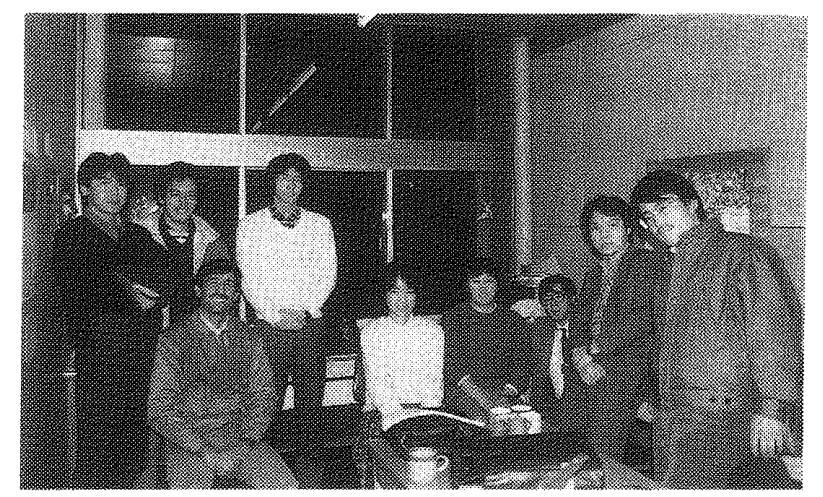

Photo 2 With Friends at Waseda University
SOFT, and held in Yokohama (November 1315, 1991). At this symposium I met several outstanding workers in the field, especially Professors Terano, Sugeno and Mukaidono. I was especially impressed by the keynote lecture entitled "Future Vision for Fuzzy Sets" delivered by Professor Terano [14] ; I translated this into Persian, and this translation was published in the Iranian journal Paik-e-Riyazi [15]. It was also at this symposium that I asked Professor Mukaidono if I could spend my sabbatical leave at the department of computer science at Meiji University. He was kind enough to agree, and hence I spent another year (October, 1992 - September,1993) in Japan, during which we published several joint papers in the field of fuzzy group theory [16-20]. Professor Mukaidono always stressed the application aspects of the theory, and in fact one of these papers [18] makes an attempt towards applying fuzzy algebraic structures.

During my sabbatical leave I attended two international meetings - The 9 th Fuzzy System Symposium (Sapporo, May 19-21, 1993) and the IFSA 93 congress at Seoul. The visit to Sapporo was very interesting for me, since it was the first time that I had been to Hokkaido, and it was so very differnt from Tokyo. At these meetings I presented papers [16,21], and I learned much more about the applications of fuzzy systems while browsing at the exhibits of commercial and research groups.

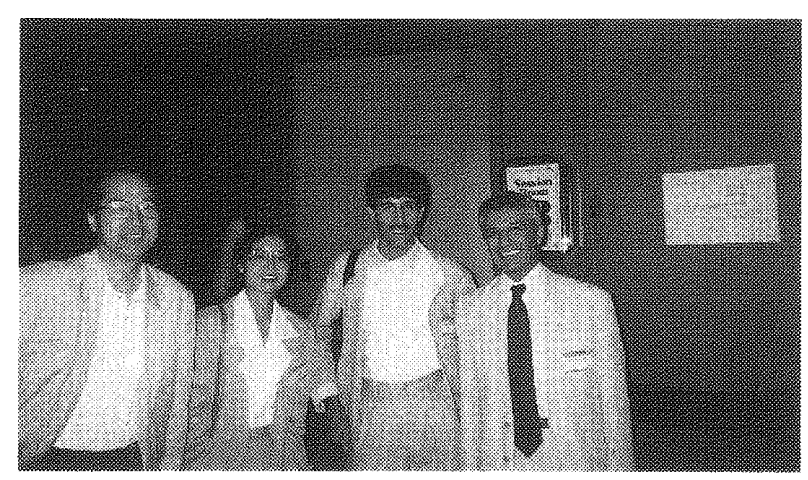

Photo 3 With Professor Mukaidono and Prof.Turksen 
One of the highlights of the sabbatical leave was the beginning of my acquaintance with Professor Hung T. Nguyen, who was a visiting professor(LIFE Chair of Fuzzy Theory) at the department of sytems science of the Tokyo Institute of Technology. I participated in his graduate lectures, and later used his lecture notes [22] when conducting a graduate course at Kerman.

I returned to Meiji University for three months starting October 1994, this time on a scholarship awarded by the Association for International Education of Japan. Professor Kuroki, whom I met then, deserves a special note of thanks - he was kind enough to send me several books and papers which were of great help in my research. During this period I revised [19], studied the subject of Approximate Reasoning, and published an article on this topic in Persian [23]. Professor Dan Ralescu was also visiting Japan, and I persuaded him and Professor Mukaidono to visit us at Kerman University and participate in the fuzzy mathematics workshop conducted under the auspices of AIMC 26, the 26 th Annual Iranian Mathematics Conference (March 28-31, 1995). A complete report of this workshop consisting of papers in English and Persian was published by the conference [25]. Professors Mukaidono and Ralescu also refereed the doctoral thesis which another of my students defended during the conference [24].

This is a summary of my relationship with Japan, especially its educational centers, the research that resulted from it, and the effect it had on research at Kerman University. Our university has become an important center for fuzzy mathematics research in Iran, and we always have graduate students working in this field.

I must once again thank the Ministry of Science and Higher Education(Monbusho) of Japan, the Association for International Educa- tion of Japan, the Waseda and Meiji universities, and Professors Hiroshio Noguchi and Masao Mukaidono for their support and encouragement throughout. I hope other Iranian students (especially from Kerman University !) will be just as lucky to avail of the opportunities I had, and also that we may see Japanese researchers in Iran .

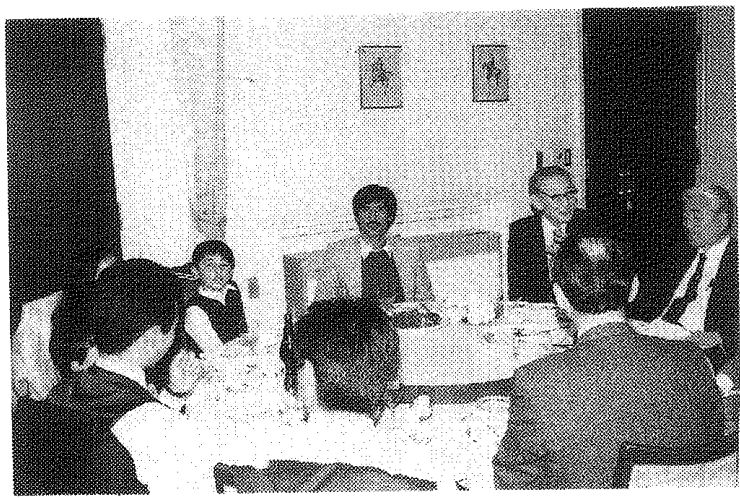

Photo 4 With Professor Noguchi

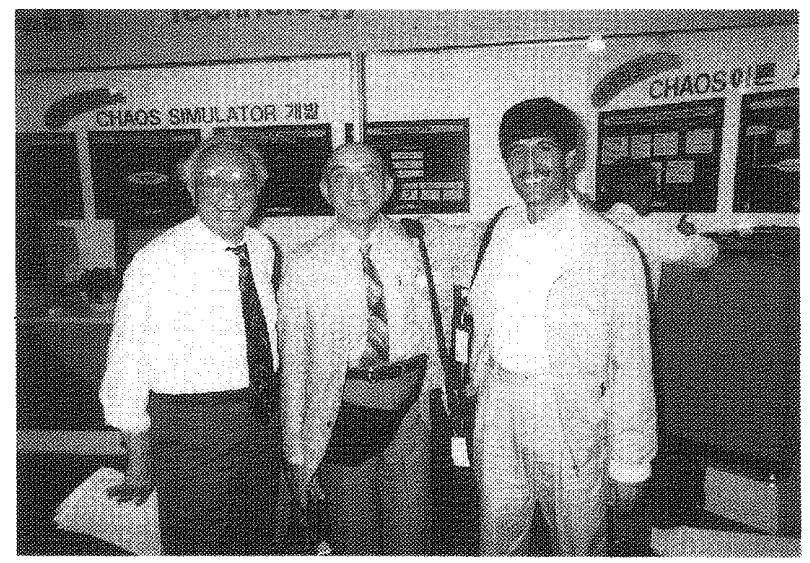

Photo 5 With Professor Zadeh

\section{REFERENCES}

1) M.Mashinchi : Retracted Neighborhood Spaces, Ars Combinatoria, 20, 83-90(1985)

2 ) M.Mashinchi : An Intermediate Value Theorem in Neighborhood Spaces, Tokyo Journ. of Math., 9, 181-186(1986)

3 ) M.Mashinchi : On Function Neighborhood Spaces, Ars Combinatoria, 20, 171-184(1987) 
4) M.Mashinchi : A Note on Hazy Manifolds, Topology and Computer Science, Kinokunya Publishing Co., 331-333 (1987)

5 ) M.Mashinchi : Some Notes on Neighborhood Spaces, Bull. Iranian Math. Soc., 15, 1, 6677 (1987)

6) M.Mashinchi : Neighborhood Spaces, Ph.D. Thesis, Waseda University, Japan (1987)

7) M.Mashinchi and M.M.Zahedi : Some Results on Redefined Fuzzy Groups, J. Sci, I. R. Iran, 1, 65-67 (1988)

8 ) M.Mashinchi and M.M.Zahedi : On Fuzzy Ideals of a Ring, J. of Sci., I. R. Iran, 1, 208210 (1990)

9) M.Mashinchi and M.M.Zahedi : A Counterexample of P.S. Das's Paper, J. Math Anal. Appl., 153, 591-592 (1990)

10) M.Mashinchi and M.M.Zahedi : On L-fuzzy Primary Submodule, Fuzzy Sets and Systems, 49, 231-236(1992)

11) M.Mashinchi and M.M.Zahedi : On the Product of T-fuzzy subgroups, Ann. Uni. Sci. Budapest, Sect. Comp., 12, 167-171(1991)

12) M.M.Zahedi : Fuzzy Research at Kerman University, Fuzzy Sets and Systems, 50, 359 (1992)

13) M.M.Zahedi : Fuzzy Algebra (Group, Ring, Module), Ph.D. Thesis, Kerman University (1990)

14) T.Terano : Future Vision for Fuzzy Engineering, Fuzzy Engineering Toward Human Friendly Systems, Proceedings of the International Fuzzy Engineering Symposium '91, 1, 38(1991)

15) M.Mashinchi : Translation of [14] into Persian, Paik-e-Riyazi, 417-432 (1992)
16) M.Mashinchi and M.Mukaidono : A Classification of Fuzzy Subgroups, Research Report of Meiji University, 9, 65, 31-36(1993)

17) M.Mashinchi and M.Mukaidono : On Generalized Fuzzy Subgroups, Proceedings of the First Asian Systems Symposium, Singapore, 11141121 (1993)

18) M.Mashinchi and M.Mukaidono: Algebraic Knowledge Classification, Journ. of Fuzzy Mathematics, 2, 2, 233-247(1994)

19) M.Mashinchi and M.Mukaidono: Generaized Fuzzy Quotient Subgroups, Fuzzy Sets and Systems, 74, 245-257(1995)

20) M.Mashinchi : On Convexity of Fuzzy Sets, Journ. of Fuzzy Math., 2, 3, 655-669(1994)

21) M.R.Maleki and M.Mashinchi : An Algorithm for Fuzzy Linear Programming, Proc. IFSA' 93, 641-643(1993)

22) H.T.Ngyuen : Lecture Notes on Fuzzy Logic, Tokyo Institute of Technology, (1993)

23) M.Mashinchi : Approximate Reasoning and implication Operators, Proc. Fuzzy Math. Workshop, AIMC26, 91-116(1995)

24) Sh.Salili : Knowledge Classification, Ph.D. Thesis, Kerman University (1995)

25) M.Mashinchi and M.M.Zahedi eds. : Proceedings of the Fuzzy Mathematics Workshop, AIMC26 (1995)

(1995 年 12 月 25 日 受付)

[問い合わせ先]

M. MASHINCHI

Associate Professor,

Faculty of Mathematics and

Computer Sciences, Kerman University, IRAN

TEL : + 98-341-263244

FAX : + 98-341-232142

Biographical Note

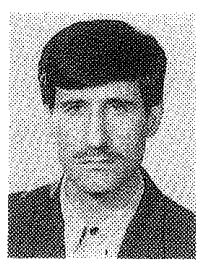

\section{MASHINCHI}

Associate Professor,

Faculty of Mathematics and

Computer Sciences, Kerman Uni-

versity

Born : 1951, Kerman, IRAN.

M.Sc. : 1976, Shiraz University, IRAN.

D.Sc. : 1987, Waseda University, JAPAN. 